\title{
An Adaptive Zero Voltage Mechanism for Boost Converter
}

\author{
Sabitha.S.A. ${ }^{1}$, V. Royna Daisy ${ }^{2}$ \\ 1. P.G.Student, Paavai Engineering College, Namakkal. \\ 2. Associate Professor/EEE, Paavai Engineering College, Namakkal.
}

\begin{abstract}
This paper proposes a zero-voltage transition in a boost converter. The presence of adaptive mechanism provides significant reduction in the converter volume, since the multiple switches is replaced by variable frequency operation with a single switch. Also, the semiconductor elements benefit from soft-switching conditions and thus, high efficiency is achieved to maintain continuity of supply. The other properties of the proposed system include no extra voltage and current stresses on the main switches and the ease of control. The proposed technique is fully analyzed for a boost converter and the reliability is achieved by Matlab simulation. The simulation result proves that a successful set point value of $60 \mathrm{~V}$ gives an accurate output voltage with input voltage of $40 \mathrm{~V}$.
\end{abstract}

Index Terms - DC-DC converter, Pulse-Width Modulation (PWM), ZVS (Zero-Voltage Switching), Adaptive Mechanism.

\section{Introduction}

Electronic power processing technology has evolved around two fundamentally different circuit schemes: duty-cycle modulation, commonly known as pulse-width modulation (PWM) and resonance. The PWM technique [1], [4], [8] processes power by interrupting the power flow and controlling the duty-cycle, thus, resulting in pulsating current and voltage waveforms. The resonant technique [10] processes power in a sinusoidal form. Due to circuit simplicity and ease of control, the PWM technique [1], [4], [8] has been used predominantly. With the advent of power MOSFET's, the switching speed choice can be as tens of megahertz. The two main difficulties with the semiconductor devices employing high switching frequency are high switching stress and switching losses [4], [8].

The electronic circuits employed in power system [7], [10], operate with some supply voltage which is usually assumed to be constant. For this purpose, a power electronic circuit like a voltage regulator [3]-[10] maintains a constant voltage irrespective of change in load current or line voltage. The DC-DC [3]-[10] converter inputs an unregulated DC voltage input and outputs a constant or regulated voltage. Compensation techniques [2], [4], vary for different control schemes [3], [5], and a small signal analysis of system is necessary to design a stable compensation circuit which can be established by PWM.

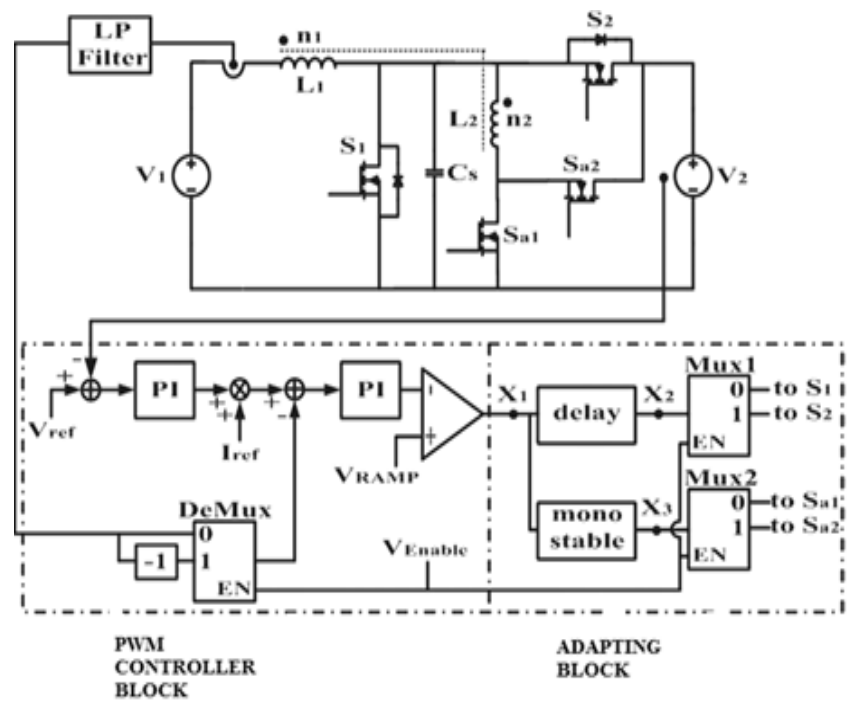

Figure 1: Block Diagram of the Existing system

A simplified mechanism for boost converter is done by making it reliable by reducing multiple switches [5], [7], to obtain a constant output without switching losses. The switches convert the voltage level between an energy storage device and the dc bus and thus constant output voltage is maintained for the 
continuity of supply. The problems of increased switching stresses and losses [4], [8], and noise associated with the converters for high switching frequency can be resolved using soft commutation techniques[1] which can be applied to basic Non-Bidirectional converters (NBDCs) [1], [8]. The most interesting approaches under soft switching condition are the Zero-Voltage-Transition (ZVT) and Zero-Current-Transition (ZCT) techniques [1], [4], in which auxiliary circuits [8] are used to assist the switches to operate. Zero-Voltage-Transition (ZVT) [3] provides a soft-switching function into conventional Pulse Width Modulation (PWM) [9] converters which reduce switching losses.

The switching devices used in DC converters with Pulse Width Modulation (PWM) control [5], [6] can be gated to synthesize desired shape of output voltage or output current at turn on and turn off conditions of switch, due to which power loss occurs. For this reasons, soft switching converters are incorporated. The complexity of power and control circuit was increasing by the use of two switches to achieve soft switching [4] which is opted with a single switch.

\section{PROPOSED SYSTEM}

In order to achieve the goal of less switching losses and stresses, the proposed boost converter has to be made capable to withstand any disturbances on the input side as well as on the output side. For this reason, initially a boost converter is designed as per standard norms and with a set value on the output side. The ZVS is assigned to the switch to obtain the resonance. A feedback loop is introduced to achieve voltage regulation where ZVS fail and a voltage other than ZVS is produced. The adaptive zero voltage mechanism includes a feed forward controller which is employed by variable frequency operation by avoiding multiple switches. The control circuit is made such that it will maintain the continuity of supply constant with the variable frequency matching of the switch off time period of the converter and the resonance time period in the aspect of getting the adaptive mechanism. The block diagram of the proposed boost converter system is as shown in figure 2 .

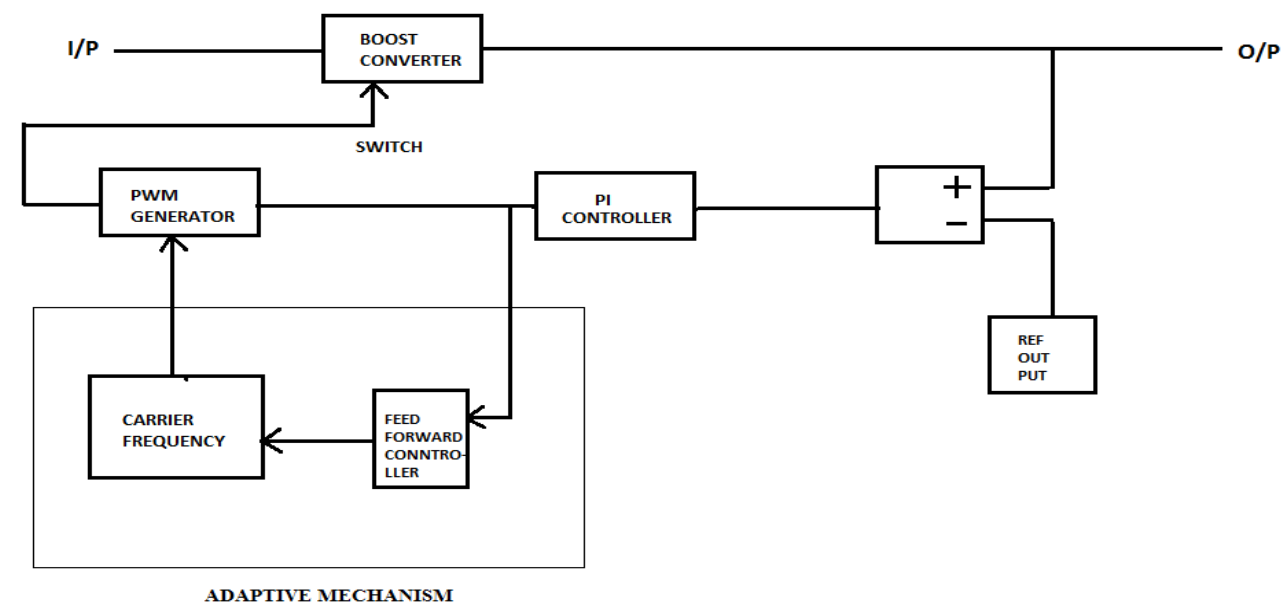

Figure 2: Block Diagram of the Proposed Boost Converter System

\section{A. Boost Mode of Operation.}

The relationship of voltage and current for an inductor is:

$$
\mathrm{i}=\frac{1}{\mathrm{~L}} \int_{0}^{\mathrm{t}} \mathrm{Vdt}+\mathrm{i}_{0}
$$

$$
\text { Or }
$$$$
V={ }_{L} \frac{d i}{d t}
$$

For a constant rectangular pulse:

$$
i=\frac{V_{t}}{L}+i_{o}
$$


From this we can see that the current is a linear ramp, when the voltage is a constant pulse. When the transistor switches on, the current is:

$$
\begin{aligned}
& i_{p k}=\frac{\left(V_{\text {in }}-V_{\text {Trans }}\right) T_{\text {on }}}{L}+i_{0} \\
& \text { Or } \\
& \Delta i=\frac{\left(V_{\text {in }}-V_{\text {Trans }}\right) T_{\text {on }}}{L}
\end{aligned}
$$

And when the transistor switches off the current is:

$$
\begin{gathered}
i_{0}=i_{i_{p k}}-\frac{\left(V_{\text {out }}-V_{\text {in }}+V_{D}\right) T_{\text {off }}}{L} \\
\text { Or } \\
\Delta i=\frac{\left(V_{\text {out }}-V_{\text {in }}+V_{D}\right)}{L} T_{\text {off }}
\end{gathered}
$$

Where $V_{D}$ is the voltage drop across the diode and $V_{\text {Trans }}$ is the voltage drop across the transistor. Note that the continuous/discontinuous boundary occurs when $\mathrm{i}_{\mathrm{o}}$ is zero. By equating through delta $\mathrm{i}$, we can solve for $\mathrm{V}_{\text {out }}$ :

$$
V_{\text {out }}=\frac{V_{\text {in }}-V_{\text {Trans }} D}{(1-D)}-V_{D}
$$

If we neglect the voltage drops across the transistor and diode then:

$$
V_{\text {out }}=\frac{V_{\text {in }}}{1-D}
$$

So it is clear that the output voltage is related directly to the duty cycle of the pulses. It can be seen from Equation (1), that the inductance is inversely proportional to the ripple current. In other words, to reduce the ripple, then use a larger inductor. Thus, in practice, a ripple current is decided upon which will give a reasonable inductance. So when choosing an inductor make sure that the saturation current of the inductor is greater than $\mathrm{i}_{\mathrm{pk}}$. Likewise, the transistor should be able to handle peak current greater than $\mathrm{i}_{\mathrm{pk}}$. The inductor should also be chosen such that it can handle the appropriate rms current. The instability can be corrected by choosing a large enough inductor so that the ripple current is greater than twice the minimum load current. When this condition is met then the inductor is always in continuous mode. This can be expressed as follows:

$$
L=\frac{\left(V_{\text {out }}-V_{\text {in }}+V_{D}\right)(1-D)}{\min \left(i_{\text {load }}\right) f}
$$

The resonant L-C circuit is introduced to create the zero voltage condition. The resonant capacitor produces a zero voltage across the switch at which instant the switch can be turned in or off. The output current can be assumed to be a constant during the high frequency resonant cycle.

\section{B. ZVS Boost Mode of Operation}

A ZVS boost PWM dc-dc converter is used for the simulation. The input voltage is kept at 10V. The load resistance is kept at 30 . The output filter capacitor is chosen as $100 \mu \mathrm{F}$. The boost inductor is selected as $\mathrm{L}_{\mathrm{s}}=2 \mathrm{mH}$. The resonant component selected is as follows: $\mathrm{L}_{\mathrm{r}}=56.83 \mu \mathrm{H}$ and $\mathrm{C}_{\mathrm{r}}=10 \mathrm{nF}$, corresponds to the resonant frequency of around $211 \mathrm{kHz}$. The switching frequency is selected as $120 \mathrm{kHz}$. The switch is controlled by a signal clock. 


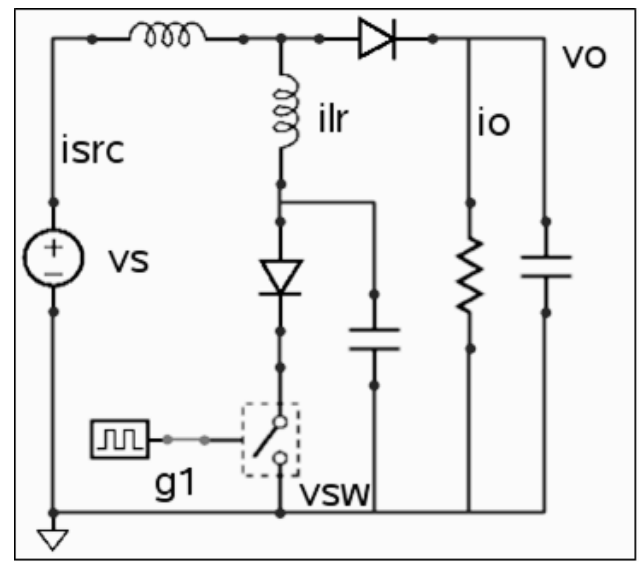

Figure 3:Proposed ZVS Boost Topology

The proposed boost converter comprising of ZVS topology is as shown in figure 3. The output can be controlled by changing the duty cycle parameter for the clock. The switch and diode are considered as ideal.

\section{A. PWM control:}

\section{IMPLEMENTATION OF THE CONTROL CIRCUIT}

The PWM block compares the compensator output with another ramp signal to give the variation in duty cycle. The source from where the ramp signal is generated leads to different control schemes. The control scheme used in the proposed system is PI control. By using pulse-width modulation (PWM) control, regulation of output voltage is achieved by varying the duty cycle of the switch. It maintains a constant switching frequency and varies the duty cycle. It is also stated that Power MOSFET's are more suitable than BJT at power output of the order of $50 \mathrm{~W}$. The voltage or current source is supplied to the analog load by means of a repeating series of on and off pulses. In resonant switched mode power supplies the control circuit regulates the output by varying the switching frequency and fixing the on or off time of the switch.

\section{B. PI control:}

The function of PI is to regulate the boost converter so that it stays close to the nominal operating point in the presence of disturbances and noise. The integral term in a PI controller causes the steady state error to reduce to zero, which is not the case for proportional-only control in general. If a controller starts from a stable state at zero error $(\mathrm{PV}=\mathrm{SP})$, then further changes by the controller will be in response to changes in other measured or unmeasured inputs to the process that impact on the process, and hence on the PV. Negative feedback is employed to maintain voltage regulation regardless of disturbances in input voltage or load current or variations in component values. The duty cycle is varied in the feedback loop to compensate for these variations. A voltage reference is used to compare with the output voltage. Sensor gain is used to scale down the output to be equal to voltage reference. The error signal thus generated is fed to the compensator which is the key part to be designed to ensure stability of total feedback loop. Compensator design affects the overshoot, steady state error and transient response of the loop. The proportional term is given by:

Where

$$
\mathrm{P}_{\text {OUT }}=\mathrm{K}_{\mathrm{p}} \mathrm{e}(\mathrm{t})
$$

$\mathrm{P}_{\text {out }}$ : Proportional output

$\mathrm{K}_{\mathrm{p}}$ : Proportional Gain, a tuning parameter

$\mathrm{e} \quad$ : Error $=\mathrm{SP}-\mathrm{PV}$ (set point-present value)

$\mathrm{t}$ : Time or instantaneous time (the present)

A high proportional gain results in a large change in the output for a given change in the error. If the proportional gain is too high, the system can become unstable. The integral term is given by:

$$
I_{\text {out }}=K_{i} \int_{0}^{t} e(\tau) d \tau
$$

Where

$\mathrm{I}_{\text {out }}:$ Integral output

$\mathrm{K}_{\mathrm{i}}$ : Integral Gain, a tuning parameter 
e $:$ Error $=\mathrm{SP}-\mathrm{PV}$

$\mathrm{t}$ : Time in the past contributing to the integral response

Since the integral term is responding to accumulated errors from the past, it can cause the present value to overshoot the set point value (cross over the set point and then create a deviation in the other direction). The outputs the proportional and integral terms are summed to calculate the output of the PI controller. At this stage, the ZVS will fail such that the OFF time is maintained at $1 \mathrm{~ms}$ to satisfy PWM when there is disturbance or variation in input side voltage of the boost converter. Larger $K_{i}$ implies steady state errors are eliminated quicker.

\section{Adaptive Mechanism:}

Adaptively regulating the supply voltage realizes potential savings without sacrificing peak performance. This technique requires a feedback loop and supply-voltage regulator to set the supply voltage to a value for any desired frequency of operation. The inductor current is a function of the load current. The converter's operation changes from continuous conduction mode CCM, to discontinuous conduction mode (DCM) when the inductor ripple current is higher than the average value. The difference between the desired performance and the measured performance (the error) acts through an adaptation law to force the model to match the real system.

The adaptive mechanism introduced in the proposed system is the feed forward controller. Combined feed forward plus feedback control can significantly improve performance over simple feedback control whenever there is a major disturbance that can be measured before it affects the process output. The economic benefits of feed forward control can come from lower operating costs and/or increased stability of the product due to its more consistent quality. Feed forward control is always used along with feedback control because a feedback control system is required to track set point changes and to suppress unmeasured disturbances that are always present in any real process.

Let $T_{R}$ be the resonant half wave time. The relation for the carrier signal frequency and the resonant frequency can be derived as follows:

$$
\begin{aligned}
T_{\text {off }} & =T_{C}[1-D] \\
\therefore & T_{\text {off }}=\frac{[1-D]}{f_{C}}=T_{R}
\end{aligned}
$$

The aim of the proposed system is:

$$
\begin{gathered}
T_{\text {off }}=T_{R} \\
T_{R}=T_{\text {total }} / 2 \\
T_{R}=1 / 2 f_{r} \\
f_{c}=\frac{[1-D]}{T_{R}} \\
\therefore f_{c}=[1-D] * 2 f_{r}
\end{gathered}
$$

The ultimate result is that the resonant frequency should coincide or match with the off period frequency for the system to maintain stability. This is achieved by variable frequency operation by varying the duty ratio. Thus a successful adaptive mechanism is developed with excellent load regulation and input line regulation. The system improves the performance and reliability with good economic consideration.

\section{Results and Discussions}

According to the discussions in the existing system, it is implemented for $50 \mathrm{~V}$ for $\mathrm{V}_{1}$ and $100 \mathrm{~V}$ for $\mathrm{V}_{2}$. The converter is operated at $100 \mathrm{kHz}$ and an output power of $240 \mathrm{~W}$. The designed values for $\mathrm{n}, \mathrm{L}_{l k}$, and $\mathrm{C}_{\mathrm{s}}$ were $1 / 3,2 \mu \mathrm{H}$ and $10 \mathrm{nF}$ respectively. The value of $\mathrm{L}_{\mathrm{M}}$ is selected as $360 \mu \mathrm{H}$. The experimental results shown in Figures 9 and 10 represent the voltage of the main and the auxiliary switches respectively. The output voltage is not an accurate continuous DC voltage.

The Figures 7 and 8 shows the output voltage with single switch which is designed for the proposed Boost converter for the zero voltage adaptive mechanism. The output obtained for the adaptive mechanism is the 
frequency resonance matching with the off time period and the boost converter successfully operated for a set value of $60 \mathrm{~V}$.The set values can be changed according to the load requirements such that the duty ratio is adjusted. The simulation diagram of the boost converter with adaptive mechanism is shown in Figure 4.

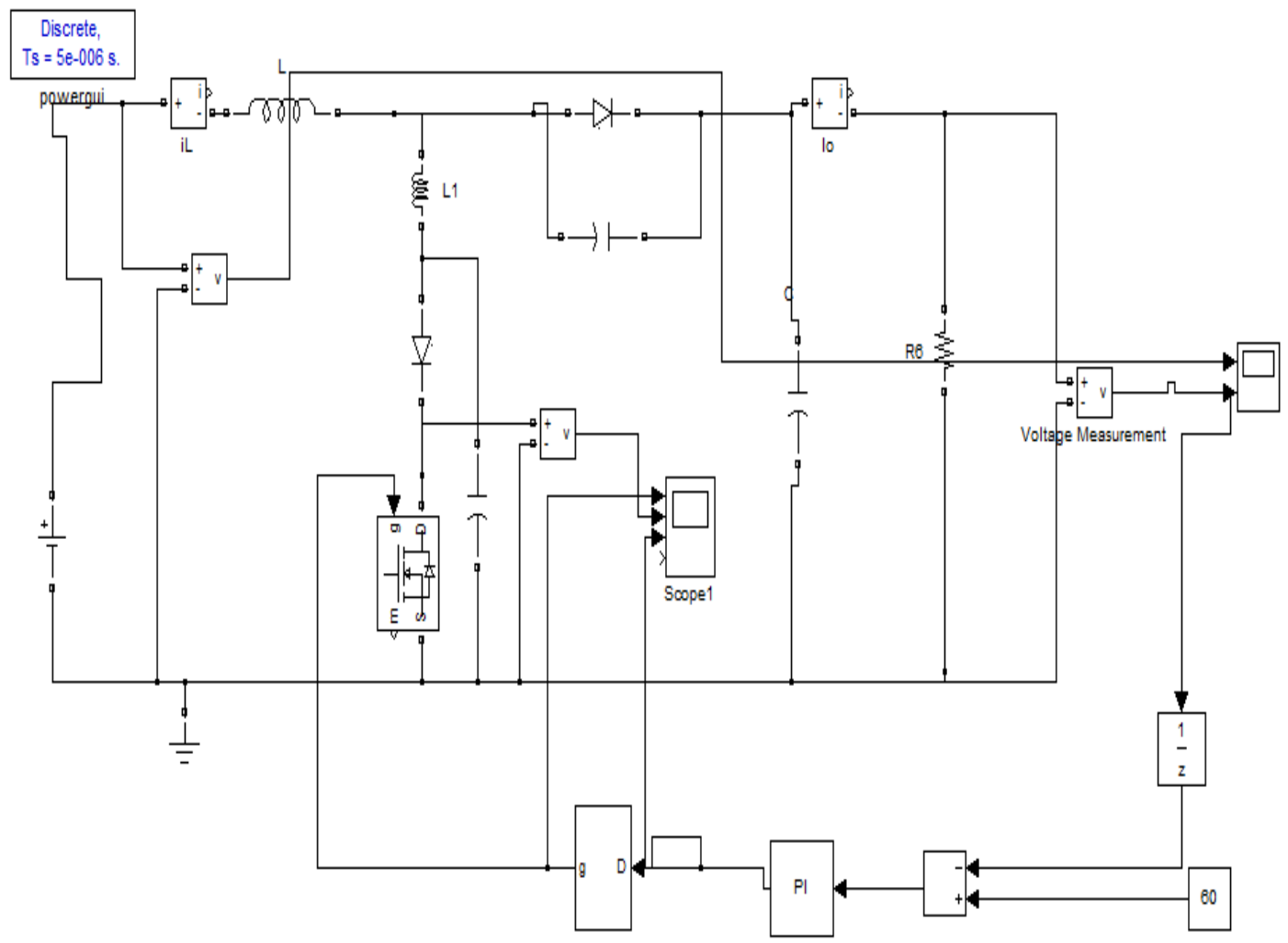

Fig 4: Simulation diagram of the Boost converter with Adaptive system

A set output value of $60 \mathrm{~V}$ is given with PI controller of values $\mathrm{K}_{\mathrm{p}}=0.001, \mathrm{~K}_{\mathrm{i}}=0.5$, output initial value $=0.7$ and sample time $=5 \mathrm{e}^{-6} \mathrm{~s}$. The load value is taken as $10 \Omega$. The $\mathrm{f}(\mathrm{u})$ value chosen is $\mathrm{f}(\mathrm{u})=((2-$ $(1.2 * \mathrm{u})) * 1) /\left(\left(150 * 5 \mathrm{e}^{-6 * 1.7))}\right.\right.$ with sample time $=-1 \mathrm{~s}$. The capacitor value across the main diode is taken as $1 \mathrm{e}^{-}$ ${ }^{100} \mathrm{~F}$. The designed values for the other elements in the circuit are as follows: $\mathrm{V}_{\text {in }}=30 \mathrm{~V}, \mathrm{~L}=2 \mathrm{e}^{-3} \mathrm{H}, \mathrm{C}=100 \mathrm{e}^{-3} \mathrm{~F}$, MOSFET: $\mathrm{R}_{\mathrm{on}}=0.1 \Omega, \mathrm{R}_{\mathrm{d}}=0.01 \Omega, \mathrm{R}_{\mathrm{s}}=1 \mathrm{e}^{5} \Omega$, Diode: $\mathrm{R}_{\mathrm{on}}=0.001 \Omega, \mathrm{V}_{\mathrm{f}}=0.8 \mathrm{~V}, \mathrm{R}(\mathrm{Load})=10 \Omega$. Unlike the soft switching in [1] and [4], it can be seen that there are no extra voltage and current stresses for the boost converter with single switch, by completely avoiding the hard switching without any auxiliary switches. With the advent of adaptive mechanism, it can be observed that the ZVS condition is well worked at almost turn-off time to match the resonance time to meet the stability requirements.

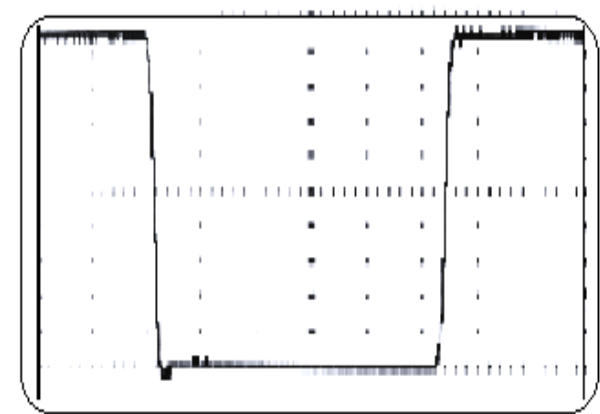

Figure 5: Voltage waveform of the existing System with the main switch operation

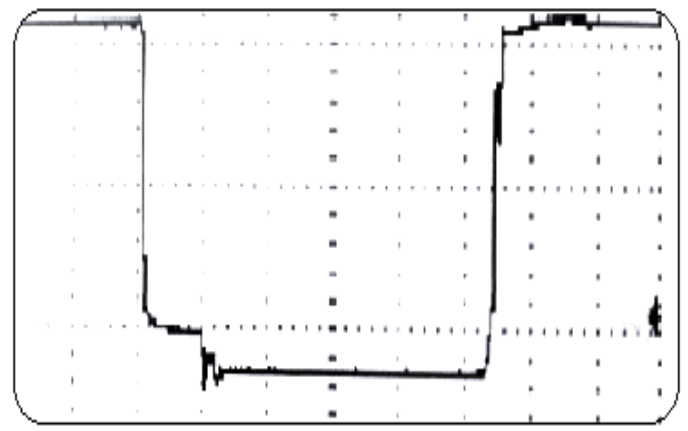

Figure 6: Voltage waveform of the existing system with the auxiliary switch operation 


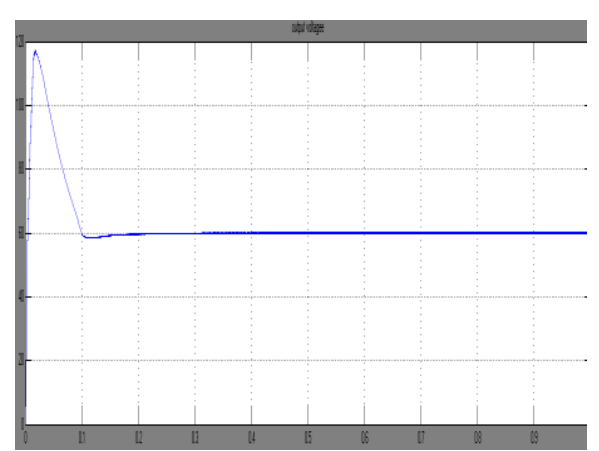

Fig 7: Output voltage with Adaptive mechanism

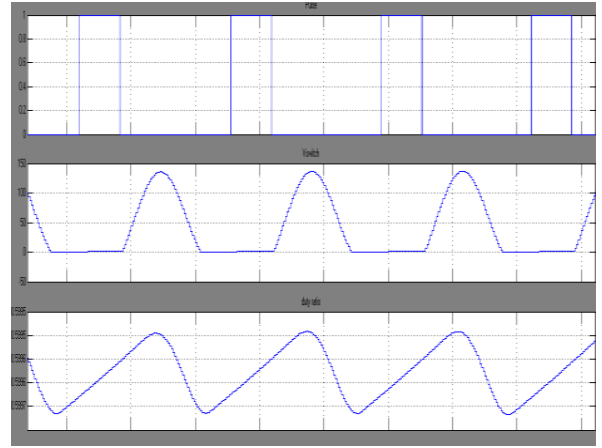

Fig 8: ZVS across the switch with the change in duty ratio

\section{Conclusion}

The main objective of the proposed system is to develop a boost converter with an adaptive mechanism to obtain a regulated output for the continuity of supply for DC link transmission. The mechanism is adopted by making it reliable such that the multiple switches are reduced to obtain a constant output without switching losses. The switches convert the voltage level between an energy storage device and the dc bus, and thus constant output voltage is maintained for the continuity of supply. Zero-voltage transition (ZVT) allows a softswitching function into conventional pulse width modulation (PWM) converters to reduce switching losses. The experimental results have been checked with Matlab simulation with desired output voltage.

\section{References}

[1] Hosein Farzanehfard and Mohammad Reza Mohammadi, "New Family of Zero- Voltage Transition PWM Bi-Directional Converters with coupled Inductors", IEEE Transaction on Industrial Electronics, VOL. 59, NO. 2, February 2012.

[2] Esam H.Ismail, "Bridgeless SEPIC rectifier with Unity Power Factor and Reduced Conduction Losses," IEEE Transactions on Industrial Electronics, VOL.56, NO.4, April 2009.

[3] Dan Chen, Ching-Jan Chen, Chun-Shih Huangand Kwang H.Liu, "Mix-Voltage Conversion for Single-Inductor Dual-Output Buck Converters," IEEE Transactions on Power Electronics, VOL.25, NO.8, August 2010.

[4] Rongjun Huang and Sudip K.Mazumder, "A Soft-Switching scheme for Multiphase DC/Pulsating DC Converter for Three-Phase High-Frequency-Link Pulse Width Modulation (PWM) Inverter," IEEE Transactions on Power Electronics, VOL.25, NO.7, July 2010.

[5] Alessandro Costabeber, Paolo Mattavelli and Stefano Saggini, "A Simple Digital Autotuning for Analog Controller in SMPS," IEEE Transactions on Power Electronics, VOL.25, NO.8, August 2010.

[6] C.Sreekumar and Vivek Agarwal, "A Hybrid Control Algorithm for Voltage Regulation in DC-DC Boost Converter," IEEE Transactions on Industrial Electronics, VOL.55, NO.6, June 2008.

[7] Leila Parsa and Suman Dwari, “An Efficient AC-DC Step-Up Converter for Low-Voltage Energy Harvesting,” IEEE Transactions on Power Electronics, VOL.25, NO.8, August 2010.

[8] Brian Laan, Gerry Moschopoulos, Pritam Das and Seyed Ahmad Mousavi, “A Non-Isolated Bidirectional ZVS-PWM Active Clamped DC-DC converter,” IEEE Transactions on Power Electronics, VOL.24, NO.2, February 2009.

[9] Carlos E.Carrejo, Enric Vidal-Idiarte, Javier Calvente and Luis Martinez Salamero, "Two-Loop Digital Sliding Mode Control of DC-DC Power converters Based on Predictive Interpolation," IEEE Transactions on Industrial Electronics, VOL.58, NO.6, June 2011.

[10] Byung-Moon Han, Jun-Young Lee and Yu-Seok Jeong, “An Isolated DC/DC converter Using High-Frequency unregulated LLC Resonant Converter for Fuel Cell Applications,” IEEE Transactions on Industrial Electronics, VOL.58, NO.7, July 2011.

\section{Author Profile:}

Sabitha.S.A. - She has received the B.Tech degree in Electrical and Electronics Engineering from P.A.Aziz College of Engineering and Technology, Trivandrum, Kerala, India under Kerala University in 2007and currently persuing M.E. in Power Electronics and Drives from Paavai Engineering College,Namakkal, Tamil Nadu, India under Anna University, Chennai (2011-2013). During 2008-2011, she has worked as Lecturer in EEE Department under M.G.University, Kerala, India.

V.Royna Daisy-She has received M.E. in Applied Electronics and currently working as Associate Professor in EEE Department in Paavai Engineering College, Namakkal, Tamil Nadu, India under Anna University, Chennai. She is currently persuing Ph.D. 